\title{
Metallomics
}

Cite this: Metallomics, 2014, 6,662

Received 12th November 2013, Accepted 3rd February 2014

DOI: $10.1039 / c 3 m t 00337 j$

www.rsc.org/metallomics

\section{Mechanisms of $\mathrm{Hg}$ species induced toxicity in cultured human astrocytes: genotoxicity and DNA-damage response}

\author{
Imke Pieper, ${ }^{a}$ Christoph A. Wehe, ${ }^{\mathrm{b}}$ Julia Bornhorst, ${ }^{\mathrm{C}}$ Franziska Ebert, ${ }^{\mathrm{c}}$ \\ Larissa Leffers, ${ }^{a}$ Michael Holtkamp, ${ }^{b}$ Pia Höseler, ${ }^{a}$ Till Weber, ${ }^{c}$ Aswin Mangerich, ${ }^{d}$ \\ Alexander Bürkle, ${ }^{d}$ Uwe Karst ${ }^{\mathrm{b}}$ and Tanja Schwerdtle ${ }^{\star a c}$
}

\begin{abstract}
The toxicologically most relevant mercury $(\mathrm{Hg})$ species for human exposure is methylmercury (MeHg). Thiomersal is a common preservative used in some vaccine formulations. The aim of this study is to get further mechanistic insight into the yet not fully understood neurotoxic modes of action of organic $\mathrm{Hg}$ species. Mercury species investigated include $\mathrm{MeHgCl}$ and thiomersal. Additionally $\mathrm{HgCl}_{2}$ was studied, since in the brain mercuric $\mathrm{Hg}$ can be formed by dealkylation of the organic species. As a cellular system astrocytes were used. In vivo astrocytes provide the environment necessary for neuronal function. In the present study, cytotoxic effects of the respective mercuricals increased with rising alkylation level and correlated with their cellular bioavailability. Further experiments revealed for all species at subcytotoxic concentrations no induction of DNA strand breaks, whereas all species massively increased $\mathrm{H}_{2} \mathrm{O}_{2}$-induced DNA strand breaks. This co-genotoxic effect is likely due to a disturbance of the cellular DNA damage response. Thus, at nanomolar, sub-cytotoxic concentrations, all three mercury species strongly disturbed poly(ADP-ribosyl)ation, a signalling reaction induced by DNA strand breaks. Interestingly, the molecular mechanism behind this inhibition seems to be different for the species. Since chronic PARP-1 inhibition is also discussed to sacrifice neurogenesis and learning abilities, further experiments on neurons and in vivo studies could be helpful to clarify whether the inhibition of poly(ADP-ribosyl)ation contributes to organic $\mathrm{Hg}$ induced neurotoxicity.
\end{abstract}

\section{Introduction}

The three most exposure relevant chemical forms of mercury $(\mathrm{Hg})$ are elemental $\mathrm{Hg}$, mercuric $\mathrm{Hg}$ and organometallic compounds. Among these methylmercury is by far the most common in the environment and in the aquatic food-chain. In addition to the consumption of inorganic $\mathrm{Hg}$ contaminated food, inorganic $\mathrm{Hg}$ exposure might occur through medicinal products. ${ }^{1}$ Inhaled elemental $\mathrm{Hg}$ vapour from dental amalgam is another source that is likely to increase internal $\mathrm{Hg}$ exposure. ${ }^{2}$ Methylmercury exposure occurs nearly exclusively via fish and seafood, with generally $80-100 \%$ of total fish $\mathrm{Hg}$ being

\footnotetext{
${ }^{a}$ Institute of Food Chemistry, University of Münster, Corrensstr. 45, 48149 Münster, Germany

${ }^{b}$ Institute of Inorganic and Analytical Chemistry, University of Münster, Corrensstr. 28/30, 48149 Münster, Germany

${ }^{c}$ Institute of Nutritional Sciences, University of Potsdam, Arthur-Scheunert-Allee 114-116, 14558 Nuthetal, Germany. E-mail: Tanja.Schwerdtle@uni-potsdam.de; Fax: +49-33200-88-5582; Tel: +49-33200-88-5580

${ }^{d}$ Molecular Toxicology Group, Department of Biology, University of Konstanz, Universitätsstraße 10, 78464 Konstanz, Germany
}

methylmercury. ${ }^{2}$ In $\mathrm{Hg}$ polluted areas in China, methylmercury contaminated rice is a further possible contributor. ${ }^{3}$ Nondietary exposure to organic $\mathrm{Hg}$ might result from the application of thiomersal (sodium 2-ethylmercurothio-salicylate). Thiomersal is used as a preservative in multidose vials of some vaccines, ${ }^{4}$ as well as in several cosmetic products and cleaning solutions for contact lenses. ${ }^{5}$ Its antimicrobial effect is based on its decomposition in aqueous medium to thiosalicylic acid and the ethylmercury cation. Rapid hydrolysis of thiomersal in aqueous biological solution has been demonstrated before. ${ }^{6}$

In 2003, the Joint FAO/WHO Expert Committee on Food Additives (JECFA) revised the PTWI for methylmercury to $1.6 \mu \mathrm{g} \mathrm{kg}^{-1}$ body weight (b.w.); developmental neurotoxicity was identified as the most sensitive toxicological endpoint. In 2006 JECFA confirmed this PTWI. ${ }^{7}$ Based on the information that beneficial nutrients in fish may have confounded previous adverse outcomes in some of these studies, the European Food Safety Authority (EFSA) Scientific Panel on Contaminants in the Food Chain established in December 2012 a TWI for methylmercury of $1.3 \mu \mathrm{g} \mathrm{kg}^{-1}$ b.w. Moreover, the Panel concluded that high fish consumers, which might include pregnant women, 
may exceed this TWI by up to six-fold. ${ }^{2}$ Regarding inorganic $\mathrm{Hg}$, in line with JECFA, ${ }^{1}$ the EFSA Panel has established a TWI of $4 \mu \mathrm{g} \mathrm{kg}{ }^{-1}$ b.w. The estimates of average dietary inorganic $\mathrm{Hg}$ exposure in Europe do not exceed the TWI. ${ }^{2}$

In general mechanisms of toxic effects of mercuric $\mathrm{Hg}$, methylmercury and thiomersal are believed to be similar. Relative toxicities of the respective species are strongly related to their bioaccessibility, accumulation and eventually metabolism or transformation to other $\mathrm{Hg}$ species in sensitive tissues. Based on limited lipophilicity mercuric $\mathrm{Hg}$ is unlikely to readily cross the blood-brain or the blood-CSF barrier. Nephrotoxicity is the most sensitive endpoint following chronic ingestion of inorganic mercury. ${ }^{1,2}$ In contrast organic $\mathrm{Hg}$ species are able to cross these barriers, allowing accumulation in the brain and neurotoxic outcomes. ${ }^{8}$

To date the underlying mechanisms of mercury species induced neurotoxicity are poorly understood. On the cellular level multiple modes of action are discussed to contribute, including the induction of oxidative stress, disturbances in calcium homeostasis, disruption of neurotransmitter systems and cytoskeletal alterations. ${ }^{9}$ With respect to genotoxicity, studies in various cultured mammalian cells have shown a genotoxic potential of the three mercuricals. However genotoxic effects arose often only at quite high, already cytotoxic concentrations. ${ }^{2-9 a}$

This study aims to gain further insights into the molecular mechanisms behind mercury species induced toxicity in human brain cells. Thus, toxic effects of methylmercury (in the form of methylmercury chloride) and thiomersal are compared in cultured human astrocytes. In the brain mercuric mercury can be formed by in situ dealkylation of the organic $\mathrm{Hg}$ species ${ }^{10}$ as well as oxidation of elemental $\mathrm{Hg} .{ }^{11}$ Therefore, cellular toxicity of mercuric $\mathrm{Hg}$ (in the form of $\mathrm{HgCl}_{2}$ ) is characterized in parallel. Endpoints studied include cytotoxicity, bioavailability, genotoxicity and co-genotoxity, as well as effects on the cellular DNA damage response.

\section{Materials and methods}

\section{Preparation of mercury species stock solutions}

$\mathrm{HgCl}_{2}$ (>99.999\% purity, Sigma-Aldrich, Deisenhofen, Germany), $\mathrm{MeHgCl}$ (>99.9\% purity, Sigma-Aldrich) and thiomersal (>97\% purity, Sigma-Aldrich) stock solutions in sterile distilled water were prepared shortly before each experiment.

\section{Cell culture and incubation with the test compounds}

Astrocytic cultures (CCF-STTG1 (CCL-185TM)) obtained from the American Type Culture Collection (Bethesda, MD, USA) were used as in vitro model systems. CCF-STTG1 cells were cultured in RPMI 1640 (Biochrom, Berlin, Germany), supplemented with 10\% FCS (PAA Laboratories, Pasching, Austria), $1.4 \mathrm{mM}$ L-glutamine (Biochrom), $100 \mathrm{U} \mathrm{mL}^{-1}$ penicillin and $100 \mathrm{mg} \mathrm{mL}{ }^{-1}$ streptomycin (PAA), under human cell culture standard conditions at $37{ }^{\circ} \mathrm{C}$ with $5 \% \mathrm{CO}_{2}$ in air and $100 \%$ humidity. Logarithmically growing cells were treated with the mercury species as described for the respective experiments.

\section{Cytotoxicity testing}

Cytotoxicity of the mercury species was elucidated after 24 and $48 \mathrm{~h}$ incubation, by quantifying their effect on cell number and lysosomal integrity. Briefly, after 24 or $48 \mathrm{~h}$ of incubation with the respective mercuricals, cells were washed with phosphate buffered saline (PBS), trypsinized and cell number was measured using an automatic cell counter CASY-TTC (Roche Innovatis AG, Germany). ${ }^{12}$ These measurements are based on noninvasive, dye-free electrical current exclusion with signal evaluation via pulse area analysis. Lysosomal integrity was assessed by the neutral red uptake test, ${ }^{13}$ which represents a well-accepted test system to assess cell viability.

\section{Cellular bioavailability}

Mercury levels in CCF-STTG1 cells were measured after $48 \mathrm{~h}$ incubation with the respective species by cold vapour atomic fluorescence spectrometry (CV-AFS, mercur Plus, Analytik Jena) or inductively coupled plasma mass spectrometry (ICP-MS, iCAP Qc, Thermo Fisher Scientific), as indicated in the respective figures. Additionally, cellular bioavailability was quantified by ICP-MS after 2 and $24 \mathrm{~h}$ incubation with the mercury species. Briefly, the mercury species exposed cells were washed with PBS and trypsinized, collected by centrifugation, washed with ice-cold PBS and the cell number as well as cell volume were measured by an automatic cell counter in each sample. After digestion of cells with $65 \% \mathrm{HNO}_{3} / 30 \% \mathrm{H}_{2} \mathrm{O}_{2}(1 / 1)$ at $95{ }^{\circ} \mathrm{C}$ as described before ${ }^{14}$ total $\mathrm{Hg}$ was quantified by CV-AFS or ICP-MS.

\section{Generation of DNA strand breaks}

DNA strand breaks were determined by the alkaline unwinding technique. ${ }^{15}$ Logarithmically growing CCF-STTG1 cells were exposed to the respective mercury species for 2,24 or $48 \mathrm{~h}$ respectively. In the case of combination experiments with $\mathrm{H}_{2} \mathrm{O}_{2}$, after preincubation $(48 \mathrm{~h})$ with the mercury species, cells were coincubated with $60 \mu \mathrm{M} \mathrm{H}_{2} \mathrm{O}_{2}$ for $5 \mathrm{~min}$. Thereafter the culture medium was removed, cells were washed with cold PBS and lesions were quantified and calculated as described before. ${ }^{15}$

\section{Cellular levels of poly(ADP-ribosyl)ation}

Cellular poly(ADP-ribosyl)ation was measured as described before. $^{15}$ Briefly, CCF-STTG1 cells were seeded on Alcian blue coated glass coverslips, cultured for $48 \mathrm{~h}$ and incubated with the respective mercury species for 2, 24 or $48 \mathrm{~h}$. Poly(ADPribosyl)ation was stimulated by $10 \mathrm{~min}$ incubation with $250 \mu \mathrm{M}$ $\mathrm{H}_{2} \mathrm{O}_{2}$. Subsequently, cells were rinsed with PBS and fixed with ice cold methanol. After fixation, cells were rinsed twice with Trisbuffered saline (TBS) and blocked in TBS/0.3\% Tween20/1\% BSA (Roth) (TTB) at $30{ }^{\circ} \mathrm{C}$ for $30 \mathrm{~min}$. Incubation with the primary anti poly(ADP-ribose) antibody $10 \mathrm{H}^{16}$ was carried out in blocking solution $(1: 300)$ at $30{ }^{\circ} \mathrm{C}$ for $45 \mathrm{~min}$, followed by repeated washing steps with TBS containing $0.3 \%$ Tween 20 . The secondary, Alexa 488-conjugated anti-mouse antibody (Invitrogen) (dilution 1:250 in TTB) was applied accordingly. Coverslips were washed again and embedded in Vectashield mounting medium containing $1 \mu \mathrm{g} \mathrm{mL}{ }^{-1}$ DAPI (Vector Laboratories Inc., Burlingame, CA, USA). 
Fluorescence analyses were performed applying a Zeiss Axio ImagerM2 wide field fluorescence microscope (Zeiss, Göttingen, Germany). At least 300 cell nuclei per slide were selected by DAPI staining. In the selected areas the relative Alexa-488 fluorescence intensities were quantified using Axio Vision (Version 4.5) imaging software (Zeiss).

\section{Relative PARP-1, PARG, LigIII $\alpha$ and XRCC1 gene expression}

Real time RT-PCR was performed for quantification of PARP-1, $P A R G$, LigIII $\alpha$ and XRCC1 mRNA levels. Briefly, $48 \mathrm{~h}$ after seeding of $2 \times 10^{6}$ astrocytes, cells were incubated with the respective mercury species for $24 \mathrm{~h}$. All further steps were performed exactly as described before. ${ }^{15}$ The respective forward (fwd) and reverse (rev) primers PARP-1 for 5'-CTTGGCCTG CACACTGTCTG-3', PARP-1 rev 5'-GCAGCGACTCTCAGATCCTG-3 (efficiency 101.3\%); PARG for 5'-CCTACTGGGTTGGTGACATT-3', $P A R G$ rev 5'-CGTAAGTGACATGCAATCGT-3' (efficiency 92.1\%); LigIII $\alpha$ for $5^{\prime}$-GATCACGTGCCACCTACCTT-3'; LigIII $\alpha$ rev $5^{\prime}$-GGC ATGGACTGTGGTCATGAG-3' (efficiency 96.9\%); XRCC1 for $5^{\prime}$-CGGATGAGAACACGGACAGT-3'; XRCC1 rev 5'-CCCCGTAAA GAAAGAAGTGC-3' (efficiency 97.4\%); $\beta$-Actin for $5^{\prime}$-TGGCATCC ACGAAACTACC-3', $\beta$-Actin rev $5^{\prime}$-GTGTTGGCGTACAGGTCTT-3' (efficiency $80.8 \%$ ) were applied. The thermal cycling program consisted of the following steps: $1.5 \mathrm{~min}$ at $95{ }^{\circ} \mathrm{C}$ to activate polymerase, 40 cycles of $30 \mathrm{~s}$ for denaturation at $95{ }^{\circ} \mathrm{C}, 1 \mathrm{~min}$ at $60{ }^{\circ} \mathrm{C}$ for annealing and elongation and final denaturation for $15 \mathrm{~s}$ at $72{ }^{\circ} \mathrm{C}$. $\beta$-Actin expression was not significantly changed by the mercury species in the observed concentration range and thus can be used in this approach as an adequate reference gene.

\section{Activity of recombinant PARP-1}

Activity of recombinant PARP-1 was quantified by an established immuno-slot-blot technique. ${ }^{15,17}$ Briefly, after 2 min preincubation of PARP-1 (0.69 ng $\left.\mu \mathrm{L}^{-1}(61 \mathrm{nM})\right)$ with the respective mercury species in preincubation buffer at room temperature, the PARP- 1 reaction was carried out for $5 \mathrm{~min}$ at $37{ }^{\circ} \mathrm{C}$ in reaction buffer. Poly(ADP-ribosyl)ation was stopped by trichloroacetic acid (TCA). After transferring respective aliquots to a PVDF membrane by a slot blotter, washing and blocking of the membrane, PAR polymers were detected by immunoblot analysis using a monoclonal PAR-antibody $(10 \mathrm{H})(1: 1000$, in blocking solution at RT for $1 \mathrm{~h}$ ) and a HRP-conjugated secondary antibody $(1: 1000$ in blocking solution at RT for $1 \mathrm{~h}$ ). Immunoreactive bands were detected by chemiluminescence using ECL prime detection reagents (GE Healthcare) and a chemiluminescence imaging system (ChemiDocTM XRS, Bio-Rad, Munich, Germany).

\section{Statistical analysis}

All experiments were carried out three times at three different days, with at least three independent measurements. Using the raw data, mean standard deviation (SD) was calculated and a statistical analysis was performed by using ANOVAOneWay and ANOVATwoWay tests. As indicated in the respective figure legends significance levels are ${ }^{*} p<0.05,{ }^{* *} p<0.01$ and ${ }^{* * *} p<0.001$.

\section{Results}

\section{Cytotoxicity in cultured astrocytes}

$\mathrm{HgCl}_{2}$ (Fig. 1A) exerted cytotoxic effects at about 10 times higher concentrations as compared to the organic mercuricals (Fig. 1B and $\mathrm{C}$ ). Cytotoxicity of $\mathrm{HgCl}_{2}$ increased with incubation time. After $48 \mathrm{~h}$ incubation the endpoint lysosomal integrity was significantly more sensitive than effects on cell number. In the case of $\mathrm{MeHgCl}$ and thiomersal, after $48 \mathrm{~h}$ incubation cell number was significantly more sensitive than lysosomal integrity. This indicates
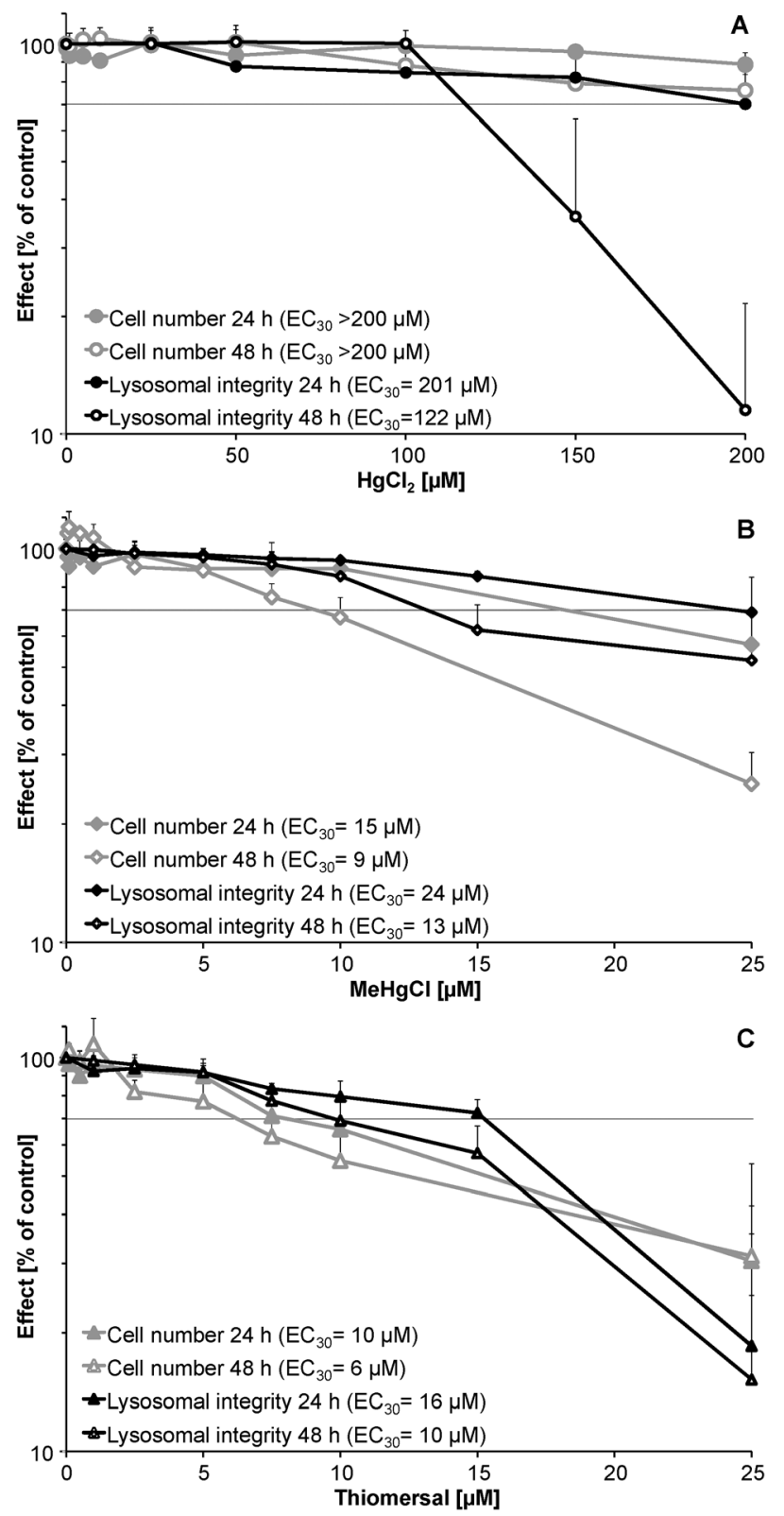

Fig. 1 Cytotoxicity of $\mathrm{HgCl}_{2}$ [A], $\mathrm{MeHgCl}[\mathrm{B}]$ and thiomersal [C] in CCF-STTG1 cells after 24 or $48 \mathrm{~h}$ incubation. Cytotoxicity was determined by a decrease in cell number and lysosomal integrity. Shown are mean values of at least 3 (cell number) or 18 (lysosomal integrity) determinations + SD. Statistical analysis of the data sets of the different cytotoxicity endpoints ( $48 \mathrm{~h}$ ) by two-way ANOVA

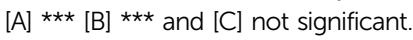


that the respective organic mercuricals and $\mathrm{HgCl}_{2}$ exert their cellular toxicity via different toxic modes of action. Time dependency of cytotoxic effects was clearly visible for $\mathrm{MeHgCl}$. In contrast cytotoxic effects of thiomersal did not significantly differ after 24 and $48 \mathrm{~h}$ incubation. Thus, after $24 \mathrm{~h}$ incubation thiomersal was the most toxic mercurical investigated.

\section{Bioavailability}

Cellular bioavailability of the respective mercury species was assessed in a time and concentration dependent manner. After $48 \mathrm{~h}$ incubation high cellular mercury levels were quantified via CV-AFS. Due to the lower limit of quantification of the applied ICP-MS method (Table 1) low cellular mercury levels were quantified by ICP-MS. As indicated in Fig. 2A-F all applied mercuricals are bioavailable to human astrocytes in a concentration dependent manner. The cellular mercury levels assessed by the two techniques fit well together.

In the case of incubation with $\mathrm{HgCl}_{2}$, cellular mercury levels increased in a time dependent manner. This is in strong contrast to the organic mercuricals (Fig. 2A-F).

\section{Determination of DNA strand breaks after mercury species incubation}

After 2, 24 and $48 \mathrm{~h}$ incubation with subcytotoxic concentrations, $\mathrm{HgCl}_{2}, \mathrm{MeHgCl}$ and thiomersal did not significantly induce DNA strand breaks in CCF-STTG1 cells (Fig. 3A-C). In the case of highly cytotoxic $\mathrm{MeHgCl}$ and thiomersal concentrations (25 $\mu \mathrm{M})$, a massive amount of DNA strand breaks (up to 13000 lesions per cell) occurred after $48 \mathrm{~h}$ of incubation.

\section{Effects of the $\mathrm{Hg}$ species on $\mathrm{H}_{2} \mathrm{O}_{2}$-induced DNA strand break formation}

After $48 \mathrm{~h}$ preincubation with the respective mercuricals a concentration dependent increase in DNA strand breaks after combined treatment with $60 \mu \mathrm{M} \mathrm{H}_{2} \mathrm{O}_{2}$ was observed, when compared to $60 \mu \mathrm{M} \mathrm{H}_{2} \mathrm{O}_{2}$ alone (Fig. 4A-C).

\section{Effects on cellular poly(ADP-ribosyl)ation}

After short-term (2 h) and long-term (24, $48 \mathrm{~h}$ ) incubation the mercury species exerted no effects on poly(ADP-ribosyl)ation in non-stimulated CCF-STTG1 cells (data not shown). Since in

Table 1 Conditions for CV-AFS and ICP-MS analysis of total mercury

\begin{tabular}{lll}
\hline Parameter & AFS & ICP-MS \\
\hline Power & $725 \mathrm{~W}$ & $1550 \mathrm{~W}$ \\
Nebulizer gas & & $1.075 \mathrm{~L} \mathrm{~min}^{-1}$ \\
Cell gas & & $8 \% \mathrm{H}_{2} \mathrm{in} \mathrm{He}^{-1}$ \\
Cell gas flow & & $5.11 \mathrm{~L} \mathrm{~min}^{-1}$ \\
Isotope & & $200 \mathrm{Hg}^{-1} \mathrm{Bi}$ \\
Internal standard & & $50 \mathrm{ng} \mathrm{L}^{-1} \mathrm{Bi}$ \\
LOD & $1.2 \mathrm{ng} \mathrm{L}^{-1}$ & $0.2 \mathrm{ng} \mathrm{L}^{-1}$ \\
LOQ & $3.5 \mathrm{ng} \mathrm{L}^{-1}$ & $0.8 \mathrm{ng} \mathrm{L}^{-1}$ \\
Reducing agent & $2 \%(\mathrm{w} / \mathrm{v}) \mathrm{SnCl}_{2} ; 10 \%(\mathrm{v} / \mathrm{v}) \mathrm{HCl}$ & \\
Jetting agent & $1 \%(\mathrm{v} / \mathrm{v}) \mathrm{HNO}_{3} ; 2 \%(\mathrm{v} / \mathrm{v}) \mathrm{HCl}$ & \\
Reductand flow & $4 \mathrm{~mL} \mathrm{~min}^{-1}$ & \\
Sample speed & $10 \mathrm{~mL} \mathrm{~min}^{-1}$ & \\
Argon flow & $170 \mathrm{~mL} \mathrm{~min}^{-1}$ &
\end{tabular}

unstressed cells the presence of poly(ADP-ribose) is in general quite low, in the next set of experiments cellular poly(ADP-ribosyl)ation was stimulated by $\mathrm{H}_{2} \mathrm{O}_{2}$, to study the impact of the $\mathrm{Hg}$ species on this DNA damage related signaling reaction.

In CCF-STTG1 cells a 2-48 $\mathrm{h}$ preincubation with subcytotoxic concentrations of $\mathrm{HgCl}_{2}(\geq 0.5 \mu \mathrm{M})$, $\mathrm{MeHgCl}(\geq 0.05 \mu \mathrm{M})$ and thiomersal $(\geq 0.05 \mu \mathrm{M})$ significantly decreased the extent of $\mathrm{H}_{2} \mathrm{O}_{2}$ induced poly(ADP-ribosyl)ation (Fig. 5A-C). Inhibition was independent of incubation time with the respective mercuricals.

\section{Effects on PARP-1, PARG, LigIII $\alpha$ and XRCC1 gene expression}

$24 \mathrm{~h}$ incubation with subcytotoxic concentrations of $\mathrm{HgCl}_{2}$ $(\geq 0.5 \mu \mathrm{M})$ led to significantly down-regulated LigIII $\alpha$ gene expression; but did not significantly alter XRCC1 and PARG mRNA levels (Table 2). PARP-1 gene expression was significantly lowered only by the highest concentration of $\mathrm{HgCl}_{2}$ applied (50 $\mu \mathrm{M}$ ). Likewise $\mathrm{HgCl}_{2}$, the organic mercuricals did not significantly disturb PARG expression (Table 2). PARP-1, XRCC1 and LigIII $\alpha$ expression were decreased by cytotoxic concentrations of $\mathrm{MeHgCl}(10 \mu \mathrm{M})$ and thiomersal $(10 \mu \mathrm{M})$. Additionally, $\mathrm{MeHgCl}$ significantly diminished LigIII $\alpha$ expression at $1 \mu \mathrm{M}$.

\section{Effects on poly(ADP-ribosyl)ation of recombinant PARP-1}

2 min preincubation of recombinant PARP-1 with $\mathrm{HgCl}_{2}$ $(\geq 2 \mu \mathrm{M}), \mathrm{MeHgCl}(\geq 18 \mu \mathrm{M})$ or thiomersal $(\geq 200 \mu \mathrm{M})$ did significantly diminish PARP-1 activity (Fig. 6A-C).

\section{Discussion}

To further understand the mechanisms behind organic mercury induced neurotoxicity, this study investigated and compared cytotoxic as well as direct and indirect genotoxic effects of $\mathrm{HgCl}_{2}$, $\mathrm{MeHgCl}$ and thiomersal in human astrocytes.

Astrocytes and microglia represent the two major cell types, which protect optimal brain function; astrocytes occupy $25 \%$ to $50 \%$ of the brain volume. ${ }^{18}$ Furthermore, evidence suggests the essential nature of interactions between neurons and astrocytes for brain function. ${ }^{19}$ Therefore, the present study was carried out in human astrocytes.

Organic mercury species are well known to cross the brain regulating barriers and subsequently accumulate in different brain areas, including the cerebellum, brain cortex and retina. ${ }^{20}$ Even though mercuric mercury cannot pass these barriers, it is present in the brain. Therefore mercuric mercury has to been taken into account, when searching for the mechanisms of mercury species induced neurotoxicity. Thus, inorganic mercury can be formed inside the brain by partial dealkylation of the organic species as well as by oxidation of $\mathrm{Hg}^{0.2,10,11}$

In the astrocytes the cytotoxicity of the mercuricals increased with rising alkylation level and fit nicely to the cellular bioavailability of the mercuricals. A similar cytotoxic order has been shown recently for these three mercury species in human T leukemic Jurkat cells. ${ }^{8}$ As possible underlying mechanisms for cytotoxicity, several endpoints are discussed, including a disturbance of proliferation, ${ }^{21} \mathrm{a}$ disruption of cellular stress, redox homeostasis ${ }^{22}$ and apoptosis. ${ }^{23}$ 

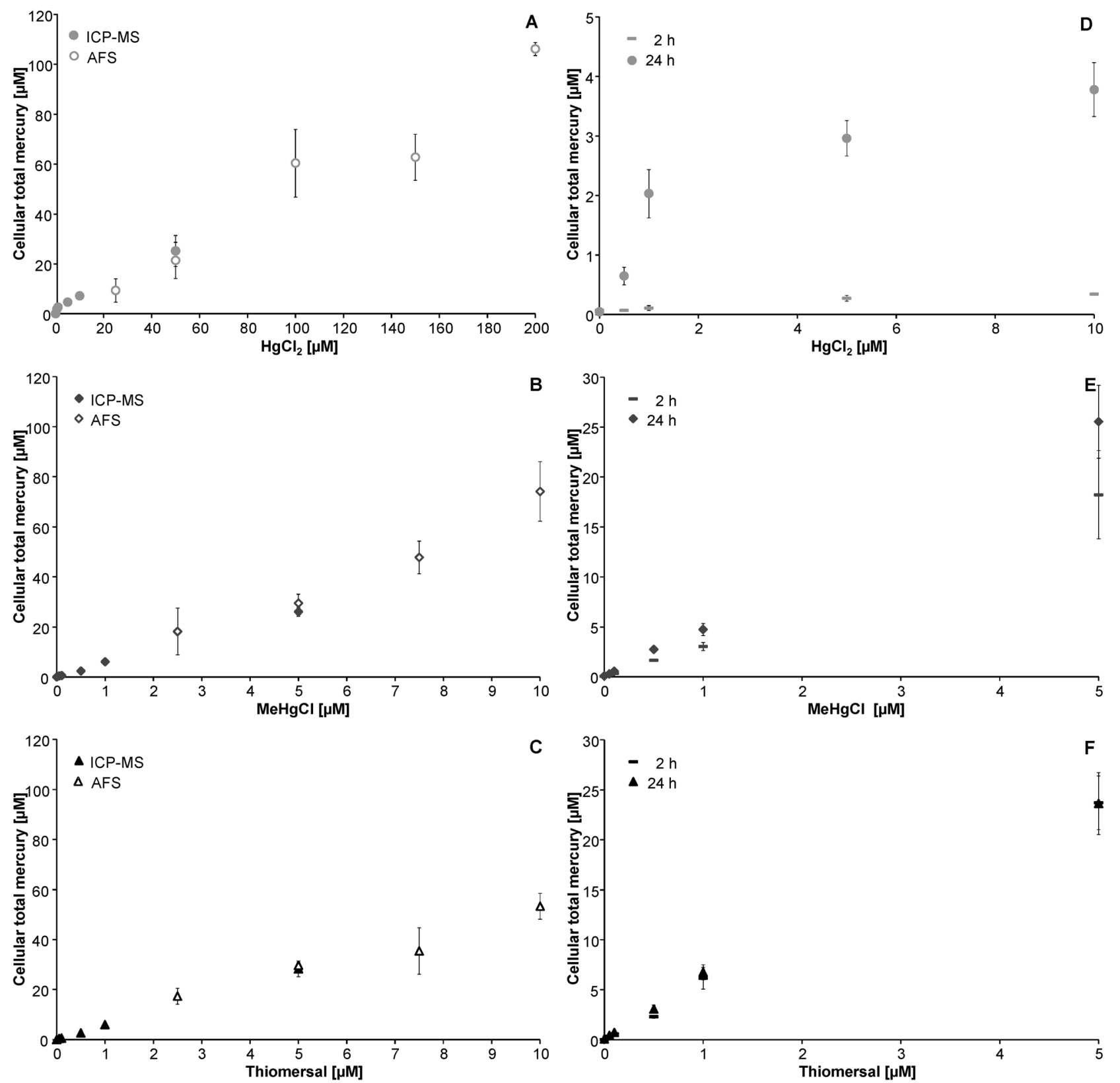

Fig. 2 Cellular bioavailability of the mercury species. Concentration dependent cellular bioavailability after $48 \mathrm{~h}$ incubation with $\left.\mathrm{HgCl} 2[\mathrm{~A}], \mathrm{MeHgCl}^{\mathrm{B}}\right] \mathrm{O}$ or thiomersal [C] as determined by AFS (open symbols) and ICP-MS (closed symbols). Time dependent cellular bioavailability of the mercury species within 2-24 $\mathrm{h}$ incubation as quantified by ICP-MS [D-F]. Shown are mean values of at least three independent determinations \pm SD.

In the present study, lysosomal integrity was affected after $\mathrm{HgCl}_{2}$ incubation at lower concentrations than cell number. Thus, in the applied astrocytes mercuric $\mathrm{Hg}$ seems to disturb the cellular energy level resulting in a collapse of the proton gradient of the lysosomes. In contrast, the two organic mercuricals affected especially the endpoint cell number, which indicates a disturbance of proliferation. Accordingly, cytogenetic studies demonstrated that both organic mercuricals strongly increased the number of binucleated cells in the respective concentration range (data not shown).

In the cytotoxic concentration range cytotoxicity of the mercuricals was accompanied by a massive increase of DNA strand breaks. Nevertheless, in the sub-cytotoxic concentration range neither $\mathrm{HgCl}_{2}, \mathrm{MeHgCl}$ nor thiomersal induced DNA strand breaks. Thus, it seems unlikely that the mercuricals induce cytotoxicity via DNA strand break induction. It is more likely that the massive increase of DNA strand breaks is a consequence of the cytotoxic process, which has been postulated before. ${ }^{24}$

Whereas the mercury species failed to increase DNA strand breaks in the sub-cytotoxic concentration range, they strongly increased $\mathrm{H}_{2} \mathrm{O}_{2}$-induced strand breaks. Our data clearly indicate that this co-genotoxic effect is due to a disturbance of the cellular DNA damage response.

One of the first nuclear reactions following DNA strand breaks induction is poly(ADP-ribosyl)ation of proteins. The respective 

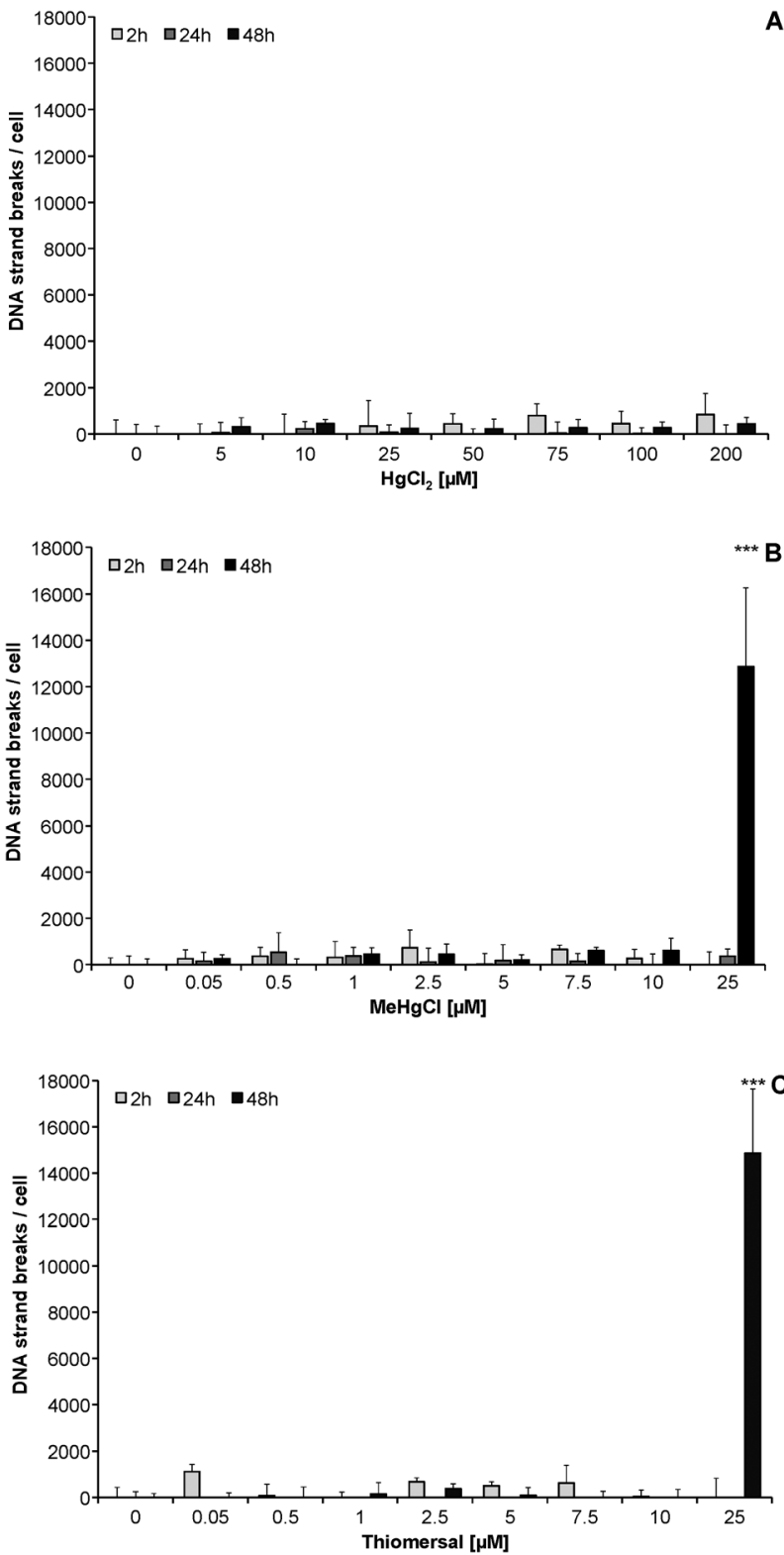

Fig. 3 Number of DNA strand breaks after 2, 24 or $48 \mathrm{~h}$ incubation with $\mathrm{HgCl}_{2}[\mathrm{~A}], \mathrm{MeHgCl}[\mathrm{B}]$ or thiomersal [C]. Shown are mean values of at least two independent experiments with three determinations each + SD.

polymerase PARP-1 is responsible for about $90 \%$ of cellular poly(ADP-ribosyl)ation. ${ }^{25}$ The negative charges of poly(ADP-ribose) are believed to cause relaxation of chromatin structure and thereby increase accessibility for other repair proteins, to carry out the repair of the DNA single strand breaks. ${ }^{26}$ Poly(ADP-ribosyl)ation of PARP-1 additionally triggers the recruitment of XRCC1, which coordinates and stimulates repair of DNA strand breaks. In the further process LIGIII $\alpha$, in association with XRCC1, efficiently ligates the respective DNA nicks. ${ }^{27}$ Thereby, LIGIII $\alpha$ activity requires the presence of poly(ADP-ribosyl)ated PARP- $1 .^{28}$

In this study poly(ADP-ribosyl)ation is identified for the first time as a novel, highly sensitive endpoint in the toxic mode of action of mercury species. For all three mercuricals a strong inhibition of this essential DNA damage response related
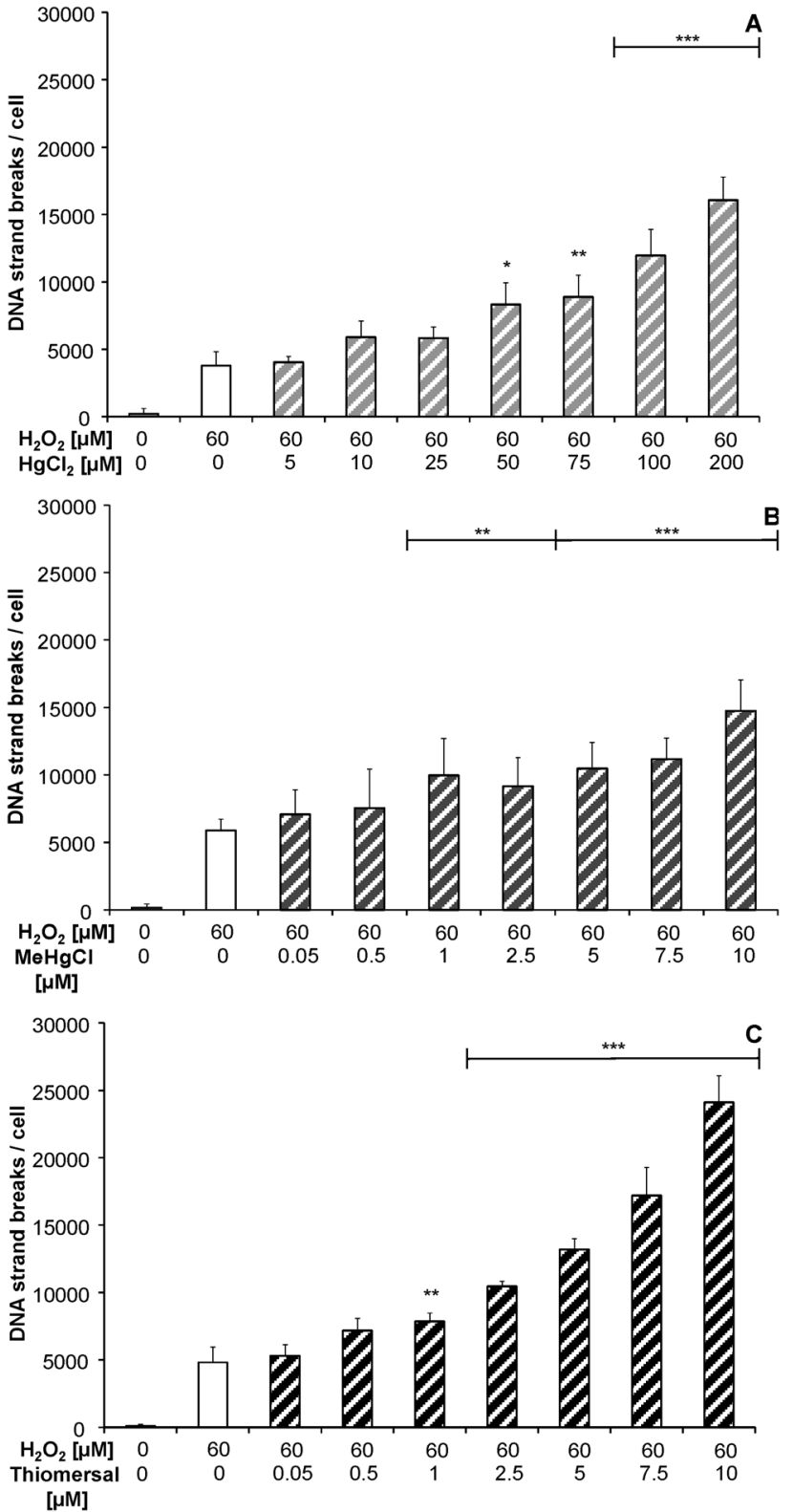

Fig. 4 Impact of a $48 \mathrm{~h}$ preincubation with $\mathrm{HgCl}_{2}[\mathrm{~A}], \mathrm{MeHgCl}[\mathrm{B}]$ or thiomersal $[\mathrm{C}]$ on the number of DNA strand breaks induced by hydrogen peroxide $(5 \mathrm{~min}, 60 \mu \mathrm{M})$ in CCF-STTG1 cells. Displayed are mean values of at least two independent experiments with three determinations each + SD.

signaling reaction was detected after $2-48 \mathrm{~h}$ incubation with subcytotoxic concentrations of the mercury species. A significant inhibition of $\mathrm{H}_{2} \mathrm{O}_{2}$-induced poly(ADP-ribosyl)ation was observed by $0.5 \mu \mathrm{M} \mathrm{HgCl}_{2}$ and $0.05 \mu \mathrm{M} \mathrm{MeHgCl}$ or thiomersal. These incubation concentrations resulted after $2 \mathrm{~h}$ incubation in cellular mercury levels of $0.04,0.20$ and $0.36 \mu \mathrm{M}$, respectively.

As underlying mechanism for the inhibition, we could exclude a mercury species induced delay of the signalling reaction process, by carrying out time-dependent poly(ADP-ribosyl)ation experiments (data not shown). The inhibition was not due to a decrease of PARP-1 gene expression. A decrease of the PARP-1 substrate $\mathrm{NAD}^{+}$ could also be excluded, especially since the observed inhibition 

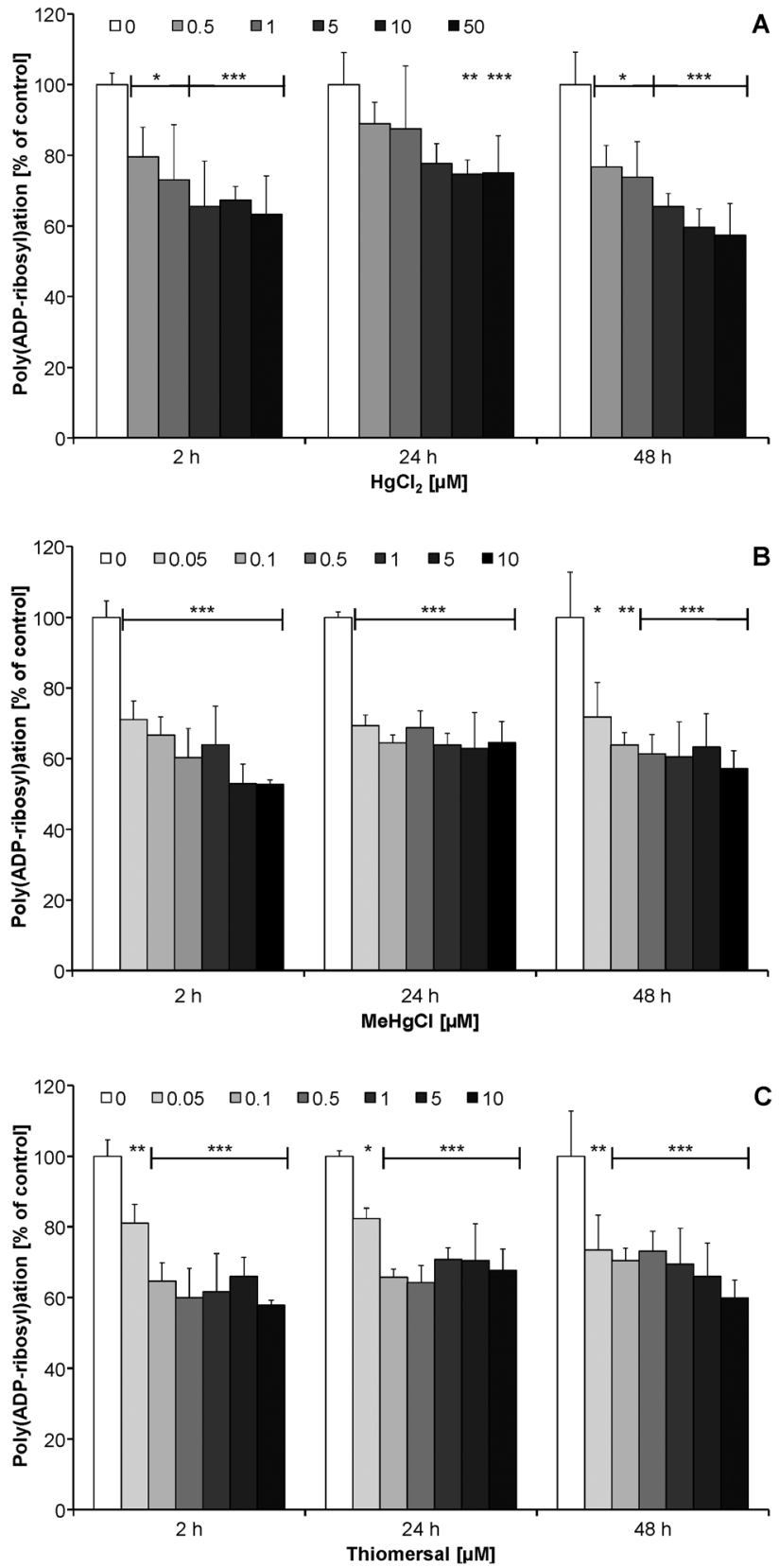

Fig. 5 Induction of poly(ADP-ribosyl)ation by $\mathrm{H}_{2} \mathrm{O}_{2}$ and inhibitory effect of 2, 24 and $48 \mathrm{~h}$ preincubation with $\mathrm{HgCl}_{2}[\mathrm{~A}], \mathrm{MeHgCl}[\mathrm{B}]$ or thiomersal [C]. Logarithmically growing CCF-STTG1 cells were preincubated with

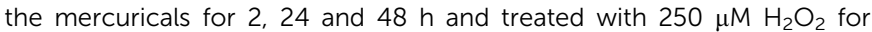
$10 \mathrm{~min}$ in the continued presence of the mercury species. Shown are mean values of at least three independent determinations with at least 200 cells each + SD .

of poly(ADP-ribosyl)ation occurred in absolutely non-cytotoxic concentrations. None of the mercury species increased gene expression of poly(ADP-ribose)glycohydrolase (PARG), with the respective protein being responsible for degradation of cellular poly(ADP-ribose). ${ }^{29}$ We cannot exclude that the mercury species stimulate PARG activity. This would result in an increased degradation of cellular poly(ADP)ribose and thus also in a decrease of cellular poly(ADP-ribosyl)ation.
Table 2 Effect of the mercury species on PARP-1, PARG, XRCC1 and Ligllla gene expression. CCF-STTG1 cells were incubated with $\mathrm{HgCl}_{2}$, $\mathrm{MeHgCl}$ or thiomersal for $24 \mathrm{~h}$. Relative gene expression was determined by real time RT-PCR; mean values of at least 2 independent determinations with 3 measurements each, referring to the control and normalized to $\beta$-Actin $\pm \mathrm{SD}$

\begin{tabular}{lllll}
\hline $\mathrm{C}[\mu \mathrm{M}]$ & & & \\
\hline & PARP-1 & PARG & XRCC1 & LigIII \\
\hline & $\mathrm{HgCl}_{2}$ & & & \\
0 & $1.00 \pm 0.08$ & $1.00 \pm 0.08$ & $1.00 \pm 0.07$ & $1.00 \pm 0.01$ \\
0.5 & $0.97 \pm 0.08$ & $0.95 \pm 0.08$ & $0.87 \pm 0.15$ & $0.89 \pm 0.09^{*}$ \\
1 & $0.91 \pm 0.13$ & $0.85 \pm 0.13$ & $1.04 \pm 0.10$ & $0.72 \pm 0.02^{* * *}$ \\
5 & $0.92 \pm 0.10$ & $0.84 \pm 0.10$ & $1.01 \pm 0.07$ & $0.69 \pm 0.05^{* * *}$ \\
10 & $0.90 \pm 0.07$ & $0.84 \pm 0.17$ & $0.95 \pm 0.04$ & $0.68 \pm 0.06^{* * *}$ \\
50 & $0.75 \pm 0.14^{* * *}$ & $0.77 \pm 0.21$ & $1.07 \pm 0.07$ & $0.71 \pm 0.06^{* * *}$
\end{tabular}

$\begin{array}{lllll} & \mathrm{MeHgCl} & & & \\ 0 & 1.00 \pm 0.12 & 1.00 \pm 0.09 & 1.00 \pm 0.04 & 1.00 \pm 0.01 \\ 0.05 & 0.95 \pm 0.08 & 1.07 \pm 0.07 & 1.05 \pm 0.06 & 0.96 \pm 0.15 \\ 0.1 & 0.94 \pm 0.16 & 1.01 \pm 0.15 & 1.09 \pm 0.11 & 0.87 \pm 0.11 \\ 0.5 & 1.03 \pm 0.09 & 1.09 \pm 0.19 & 1.06 \pm 0.07 & 1.01 \pm 0.13 \\ 1 & 1.03 \pm 0.14 & 1.11 \pm 0.12 & 1.09 \pm 0.09 & 0.72 \pm 0.08^{* *} \\ 10 & 0.71 \pm 0.15^{* *} & 1.20 \pm 0.15 & 0.78 \pm 0.06^{* * *} & 0.65 \pm 0.18^{* * *}\end{array}$

$\begin{array}{lllll} & \text { Thiomersal } & & & \\ 0 & 1.00 \pm 0.10 & 1.00 \pm 0.05 & 1.03 \pm 0.08 & 1.00 \pm 0.04 \\ 0.05 & 1.06 \pm 0.09 & 1.02 \pm 0.08 & 1.15 \pm 0.13 & 1.01 \pm 0.09 \\ 0.1 & 1.00 \pm 0.17 & 0.94 \pm 0.13 & 1.13 \pm 0.16 & 0.88 \pm 0.14 \\ 0.5 & 0.95 \pm 0.06 & 1.00 \pm 0.11 & 1.00 \pm 0.07 & 0.85 \pm 0.10 \\ 1 & 0.87 \pm 0.12 & 0.94 \pm 0.15 & 1.03 \pm 0.16 & 0.91 \pm 0.04 \\ 10 & 0.76 \pm 0.13^{*} & 1.08 \pm 0.17 & 0.71 \pm 0.09^{* * *} & 0.69 \pm 0.08^{* * *}\end{array}$

As possible mechanism for the disturbance of this essential cellular signalling reaction an inhibition of PARP-1 activity might be possible. All three mercuricals were able to diminish the activity of recombinant PARP-1. Here the inhibitory effect decreased with increasing alkylation level of the mercuricals. In the case of $\mathrm{HgCl}_{2}$ and $\mathrm{MeHgCl}$ the low micromolar concentrations, which effectively disturbed recombinant PARP-1 activity, are likely to be reached in the cellular system. In the astrocytes disturbance might at least partly be due to an interaction of the mercuricals with cellular PARP-1 activity. One possible mechanism could be a direct interaction of $\mathrm{HgCl}_{2}$ and $\mathrm{MeHgCl}$ with the zinc finger structures ${ }^{30}$ of PARP-1. In the case of thiomersal, the recombinant PARP-1 protein data reveal that this mechanism is unlikely to be relevant for the cellular system. Nevertheless, thiomersal might inactivate cellular PARP-1 activity also indirectly, e.g. by a generation of reactive oxygen species or also by a metabolism of the mercurical to another more effective mercury species. This might be clarified by cellular mercury speciation studies in the future.

Since $\mathrm{MeHgCl}$ and especially $\mathrm{HgCl}_{2}(\geq 0.5 \mu \mathrm{M})$ downregulate LigIII $\alpha$ gene expression, repair of strand breaks might additionally be blocked by a disturbance of the ligation process; thiomersal affected LigIII $\alpha$ expression only in a cytotoxic concentration.

In summary, the single mercury species affect common but also different targets of the cellular stress response. Thus, in the case of a mixed mercury species exposure in brain target cells, the DNA damage response will be efficiently disturbed. Regarding the inhibition of the DNA strand break repair, all three mercuricals can disturb the signalling reaction poly(ADP-ribosyl)ation. 

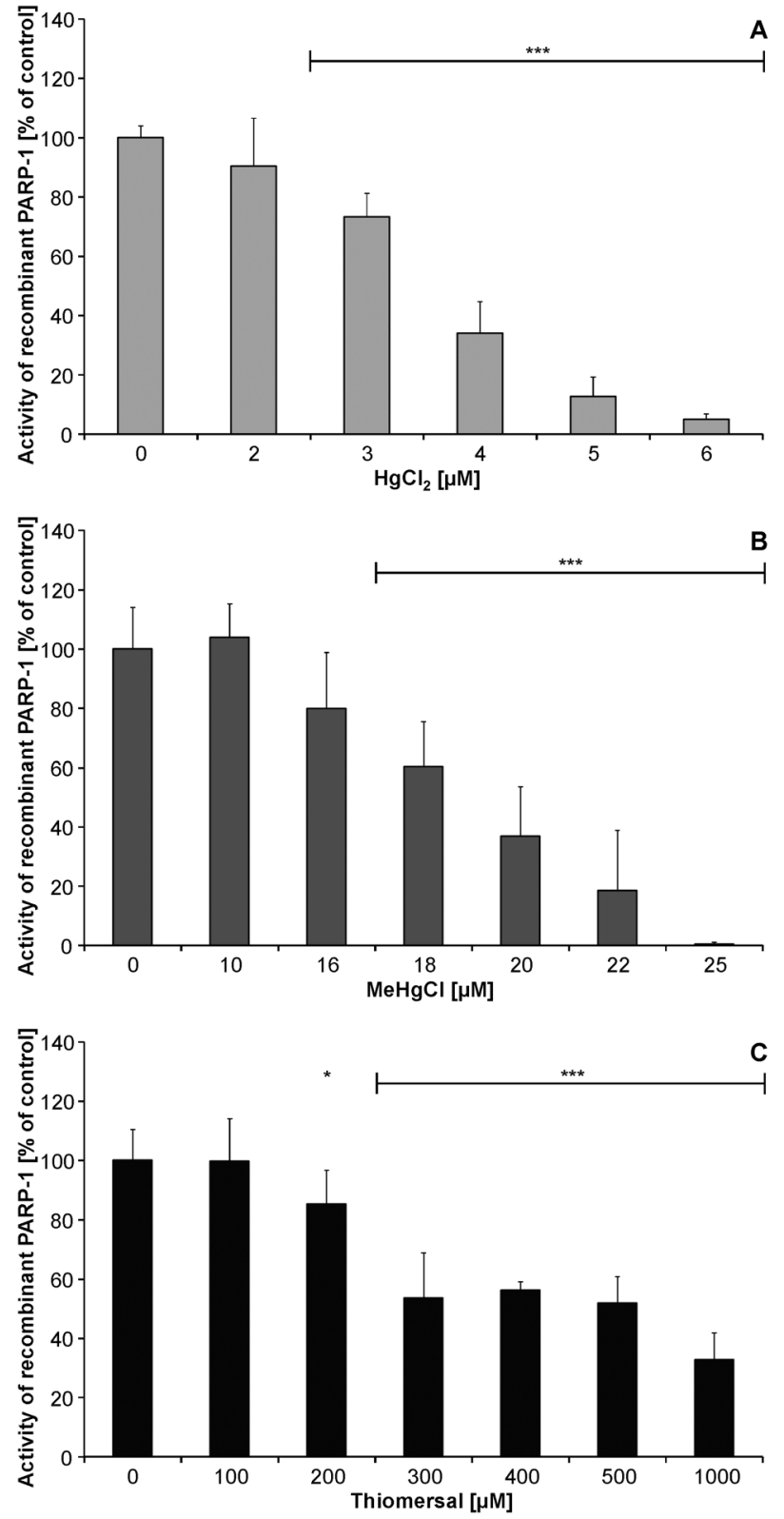

Fig. 6 Impact of $\mathrm{HgCl}_{2}[\mathrm{~A}], \mathrm{MeHgCl}[\mathrm{B}]$ or thiomersal [C] on the activity of recombinant PARP-1. Shown are mean values of at least three independent determinations with three measurements each + SD.

$\mathrm{HgCl}_{2}$ and $\mathrm{MeHgCl}$ downregulate LigIII $\alpha$, and $\mathrm{HgCl}_{2}$ can additionally disturb the energy level and thus limit cellular ATP, which is necessary for the ligation process. Poly(ADPribosyl)ation is affected by the respective mercuricals at concentrations as low as $50 \mathrm{nM}$ and most likely by different mechanisms. This endpoint should be further studied in experiments applying mixed mercury species exposure, to rule out if the disturbance of this essential signalling reaction contributes to organic mercury induced neurotoxicity. Hence it is well known that the cellular reduction of DNA damage induced poly(ADPribosyl)ation has serious consequences. DNA strand breaks, but also other DNA lesions, including oxidative base modifications, are no longer efficiently repaired and might accumulate.
Subsequently, astrocytes become dysfunctional and/or undergo cell death. Death of astrocytes can disturb neural development, but also cause death of neurons. ${ }^{31}$ Furthermore, it is possible that the mercuricals disturb damage induced poly(ADP-ribosyl)ation also in neurons. This has to be confirmed in future studies, especially since abnormal neuronal development or even a loss of neurons seems to play a role in many chronic neurodegenerative diseases such as ischaemia, Alzheimer's, Parkinson's and Huntington's diseases. ${ }^{32}$ Furthermore, continued PARP-1 inhibition is discussed to result in a disturbance of neurogenesis and learning abilities in perinatal CNS. ${ }^{33}$ Whether there is a correlation to the decrement in intelligence and impairment of memory in children highly exposed to mercury species, ${ }^{34}$ should be tested in further studies.

\section{Acknowledgements}

The authors would like to thank Prof. Dr Hans-Joachim Galla (Institute of Biochemistry, University of Münster, Germany) for the CCF-STTG1 cells and PD Dr. Sascha Beneke (Institute of Veterinary Pharmacology and Toxicology, University of Zürich Switzerland) for helping us with the recombinant PARP-1 assay.

\section{References}

$1 \mathrm{FAO} / \mathrm{WHO}$, Safety evaluation of certain food additives and contaminants. Mercury. World Health Organization, JECFA, Geneva, 2011.

2 EFSA, Scientific Opinion on the risk for public health related to the presence of mercury and methylmercury in food1, EFSA J., 2012, 10, 1-241.

3 P. Li, X. Feng and G. Qiu, Methylmercury exposure and health effects from rice and fish consumption: a review, Int. J. Environ. Res. Public Health, 2010, 7, 2666-2691, DOI: 10.3390/ijerph7062666.

4 USFDA, United States Food Drug Administration, Center for Biologics Evaluation and Research. Thimerosal in vaccines. Available from http://www.fda.gov/cber/vaccine/thimerosal. htm\#1/. 2009.

5 M. Aschner, N. Onishchenko and S. Ceccatelli, Toxicology of alkylmercury compounds, Met. Ions Life Sci., 2010, 7, 403-434, DOI: 10.1039/BK9781847551771-00403.

6 (a) R. Janzen, M. Schwarzer, M. Sperling, M. Vogel, T. Schwerdtle and U. Karst, Adduct formation of Thimerosal with human and rat hemoglobin: a study using liquid chromatography coupled to electrospray time-of-flight mass spectrometry (LC/ESI-TOF-MS), Metallomics, 2011, 3, 847-852, DOI: 10.1039/c1mt00043h; (b) S. Trümpler, W. Lohmann, B. Meermann, W. Buscher, M. Sperling and U. Karst, Interaction of thimerosal with proteins-ethylmercury adduct formation of human serum albumin and beta-lactoglobulin A, Metallomics, 2009, 1, 87-91, DOI: 10.1039/B815978e.

7 (a) FAO/WHO, Safety evaluation of certain food additives and contaminants. Methylmercury, World Health Organization, JECFA, Geneva, 2004, pp. 565-623; (b) FAO/WHO, Safety evaluation of 
certain food additives and contaminants. Methylmercury, World Health Organization, JECFA, Geneva, 2007, pp. 269-315.

8 G. Guzzi, P. D. Pigatto, F. Spadari and C. A. La Porta, Effect of thimerosal, methylmercury, and mercuric chloride in Jurkat T Cell Line, Interdiscip. Toxicol., 2012, 5, 159-161, DOI: 10.2478/v10102-012-0026-1.

9 (a) J. G. Dorea, Integrating experimental (in vitro and in vivo) neurotoxicity studies of low-dose thimerosal relevant to vaccines, Neurochem. Res., 2011, 36, 927-938, DOI: 10.1007/s11064-011-0427-0; (b) J. G. Dorea, M. Farina and J. B. Rocha, Toxicity of ethylmercury (and Thimerosal): a comparison with methylmercury, J. Appl. Toxicol., 2013, 33, 700-711, DOI: 10.1002/jat.2855; (c) M. Duszczyk-Budhathoki, M. Olczak, M. Lehner and M. D. Majewska, Administration of thimerosal to infant rats increases overflow of glutamate and aspartate in the prefrontal cortex: protective role of dehydroepiandrosterone sulfate, Neurochem. Res., 2012, 37, 436-447, DOI: 10.1007/s11064-011-0630-z; (d) M. Farina, J. B. Rocha and M. Aschner, Mechanisms of methylmercury-induced neurotoxicity: evidence from experimental studies, Life sci., 2011, 89, 555-563, DOI: 10.1016/j.lfs.2011.05.019; (e) N. Mori, A. Yasutake, M. Marumoto and K. Hirayama, Methylmercury inhibits electron transport chain activity and induces cytochrome c release in cerebellum mitochondria, J. Toxicol. Sci., 2011, 36, 253-259; $(f)$ C. F. Huang, S. H. Liu, C. J. Hsu and S. Y. Lin-Shiau, Neurotoxicological effects of low-dose methylmercury and mercuric chloride in developing offspring mice, Toxicol. Lett., 2011, 201, 196-204, DOI: 10.1016/j.toxlet.2010.12.016; $(g)$ M. Farina, M. Aschner and J. B. Rocha, Oxidative stress in MeHg-induced neurotoxicity, Toxicol. Appl. Pharmacol., 2011, 256, 405-417, DOI: 10.1016/ j.taap.2011.05.001.

10 (a) T. W. Clarkson and L. Magos, The toxicology of mercury and its chemical compounds, Crit. Rev. Toxicol., 2006, 36, 609-662, DOI: 10.1080/10408440600845619; (b) J. L. Rodrigues, J. M. Serpeloni, B. L. Batista, S. S. Souza and F. Barbosa, Jr., Identification and distribution of mercury species in rat tissues following administration of thimerosal or methylmercury, Arch. Toxicol., 2010, 84, 891-896, DOI: 10.1007/s00204-010-0538-4.

11 G. M. Richardson, R. Wilson, D. Allard, C. Purtill, S. Douma and J. Graviere, Mercury exposure and risks from dental amalgam in the US population, post-2000, Sci. Total Environ., 2011, 409, 4257-4268, DOI: 10.1016/j.scitotenv.2011.06.035.

12 J. Bornhorst, F. Ebert, H. Lohren, H. U. Humpf, U. Karst and T. Schwerdtle, Effects of manganese and arsenic species on the level of energy related nucleotides in human cells, Metallomics, 2012, 4, 297-306, DOI: 10.1039/c2mt00164k.

13 J. Bornhorst, C. A. Wehe, S. Hüwel, U. Karst, H. J. Galla and T. Schwerdtle, Impact of manganese on and transfer across blood-brain and blood-cerebrospinal fluid barrier in vitro, J. Biol. Chem., 2012, 287, 17140-17151, DOI: 10.1074/jbc.M112.344093.

14 J. Bornhorst, F. Ebert, A. Hartwig, B. Michalke and T. Schwerdtle, Manganese inhibits poly(ADP-ribosyl)ation in human cells: a possible mechanism behind manganeseinduced toxicity?, J. Environ. Monit., 2010, 12, 2062-2069, DOI: $10.1039 /$ c0em00252f.
15 J. Bornhorst, S. Meyer, T. Weber, C. Böker, T. Marschall, A. Mangerich, S. Beneke, A. Bürkle and T. Schwerdtle, Molecular mechanisms of Mn induced neurotoxicity: RONS generation, genotoxicity, and DNA-damage response, Mol. Nutr. Food Res., 2013, 57, 1255-1269, DOI: 10.1002/mnfr.201200758.

16 H. Kawamitsu, H. Hoshino, H. Okada, M. Miwa, H. Momoi and T. Sugimura, Monoclonal antibodies to poly(adenosine diphosphate ribose) recognize different structures, Biochemistry, 1984, 23, 3771-3777.

17 S. Beneke, A. L. Scherr, V. Ponath, O. Popp and A. Bürkle, Enzyme characteristics of recombinant poly(ADP-ribose) polymerases- 1 of rat and human origin mirror the correlation between cellular poly(ADP-ribosyl)ation capacity and species-specific life span, Mech. Ageing Dev., 2010, 131, 366-369, DOI: 10.1016/j.mad.2010.04.003.

18 (a) H. K. Kimelberg and M. D. Norenberg, Astrocytes, Sci. Am., 1989, 260, 66-72, 74, 76; (b) M. Ni, X. Li, Z. Yin, M. Sidoryk-Wegrzynowicz, H. Jiang, M. Farina, J. B. Rocha, T. Syversen and M. Aschner, Comparative study on the response of rat primary astrocytes and microglia to methylmercury toxicity, Glia, 2011, 59, 810-820, DOI: 10.1002/glia.21153.

19 E. E. Benarroch, Neuron-astrocyte interactions: partnership for normal function and disease in the central nervous system. Mayo Clinic proceedings, Mayo Clin. Proc., 2005, 80, 1326-1338, DOI: 10.4065/80.10.1326.

20 (a) M. Berlin, R. Zalups and B. A. Fowler, Mercury in Handbook on the Toxicology of Metals, 2007, pp. 675-729; (b) T. W. Clarkson, Molecular and ionic mimicry of toxic metals, Annu. Rev. Pharmacol. Toxicol., 1993, 33, 545-571, DOI: 10.1146/annurev.pa.33.040193.002553; (c) J. C. Erie, J. A. Butz, J. A. Good, E. A. Erie, M. F. Burritt and J. D. Cameron, Heavy metal concentrations in human eyes, Am. J. Ophthalmol., 2005, 139, 888-893, DOI: 10.1016/ j.ajo.2004.12.007.

21 M. Xu, C. Yan, Y. Tian, X. Yuan and X. Shen, Effects of low level of methylmercury on proliferation of cortical progenitor cells, Brain Res., 2010, 1359, 272-280, DOI: 10.1016/ j.brainres.2010.08.069.

22 (a) M. Ni, X. Li, Z. Yin, H. Jiang, M. Sidoryk-Wegrzynowicz, D. Milatovic, J. Cai and M. Aschner, Methylmercury induces acute oxidative stress, altering Nrf2 protein level in primary microglial cells, Toxicol. Sci., 2010, 116, 590-603, DOI: 10.1093/toxsci/kfq126; (b) S. J. James, W. Slikker, 3rd, S. Melnyk, E. New, M. Pogribna and S. Jernigan, Thimerosal neurotoxicity is associated with glutathione depletion: protection with glutathione precursors, Neurotoxicology, 2005, 26, 1-8, DOI: 10.1016/j.neuro.2004.07.012.

23 K. J. Woo, T. J. Lee, J. H. Bae, B. C. Jang, D. K. Song, J. W. Cho, S. I. Suh, J. W. Park and T. K. Kwon, Thimerosal induces apoptosis and G2/M phase arrest in human leukemia cells, Mol. Carcinog., 2006, 45, 657-666, DOI: 10.1002/mc.20202.

24 (a) A. W. Tann, I. Boldogh, G. Meiss, W. Qian, B. Van Houten, S. Mitra and B. Szczesny, Apoptosis induced by persistent single-strand breaks in mitochondrial genome: 
critical role of EXOG ( $5^{\prime}$-EXO/endonuclease) in their repair, J. Biol. Chem., 2011, 286, 31975-31983, DOI: 10.1074/ jbc.M110.215715; (b) X. Wu, H. Liang, K. A. O'Hara, J. C. Yalowich and B. B. Hasinoff, Thiol-modulated mechanisms of the cytotoxicity of thimerosal and inhibition of DNA topoisomerase II alpha, Chem. Res. Toxicol., 2008, 21, 483-493, DOI: 10.1021/tx700341n; (c) D. S. Baskin, H. Ngo and V. V. Didenko, Thimerosal induces DNA breaks, caspase- 3 activation, membrane damage, and cell death in cultured human neurons and fibroblasts, Toxicol. Sci., 2003, 74, 361-368, DOI: 10.1093/toxsci/kfg126.

25 A. Mangerich and A. Bürkle, How to kill tumor cells with inhibitors of poly(ADP-ribosyl)ation, Int. J. Cancer, 2011, 128, 251-265, DOI: 10.1002/ijc.25683.

26 F. Dantzer, J. C. Ame, V. Schreiber, J. Nakamura, J. Menissier-de Murcia and G. de Murcia, Poly(ADP-ribose) polymerase-1 activation during DNA damage and repair, Methods Enzymol., 2006, 409, 493-510, DOI: 10.1016/S00766879(05)09029-4.

27 I. D. Odell, J. E. Barbour, D. L. Murphy, J. A. Della-Maria, J. B. Sweasy, A. E. Tomkinson, S. S. Wallace and D. S. Pederson, Nucleosome disruption by DNA ligase IIIXRCC1 promotes efficient base excision repair, Mol. Cell. Biol., 2011, 31, 4623-4632, DOI: 10.1128/MCB.05715-11.

28 J. B. Leppard, Z. Dong, Z. B. Mackey and A. E. Tomkinson, Physical and functional interaction between DNA ligase IIIalpha and poly(ADP-Ribose) polymerase 1 in DNA single-strand break repair, Mol. Cell. Biol., 2003, 23, 5919-5927.
29 K. Erdelyi, P. Bai, I. Kovacs, E. Szabo, G. Mocsar, A. Kakuk, C. Szabo, P. Gergely and L. Virag, Dual role of poly(ADPribose) glycohydrolase in the regulation of cell death in oxidatively stressed A549 cells, FASEB J., 2009, 23, 3553-3563, DOI: 10.1096/fj.09-133264 fj.09-133264 [pii].

30 M. L. Meyer-Ficca, R. G. Meyer, E. L. Jacobson and M. K. Jacobson, Poly(ADP-ribose) polymerases: managing genome stability, Int. J. Biochem. Cell Biol., 2005, 37, 920-926, DOI: 10.1016/j.biocel.2004.09.011.

31 P. M. Rappold and K. Tieu, Astrocytes and therapeutics for Parkinson's disease, Neurotherapeutics, 2010, 7, 413-423, DOI: 10.1016/j.nurt.2010.07.001 S1933-7213(10)00087-5 [pii]. 32 (a) M. F. Mehler and S. Gokhan, Mechanisms underlying neural cell death in neurodegenerative diseases: alterations of a developmentally-mediated cellular rheostat, Trends Neurosci., 2000, 23, 599-605; (b) A. M. Gorman, Neuronal cell death in neurodegenerative diseases: recurring themes around protein handling, J. Cell. Mol. Med., 2008, 12, 2263-2280, DOI: 10.1111/j.1582-4934.2008.00402.x.

33 T. M. Kauppinen, Multiple roles for poly(ADP-ribose)polymerase-1 in neurological disease, Neurochem. Int., 2007, 50, 954-958, DOI: 10.1016/j.neuint.2006.11.010.

34 (a) P. Grandjean, P. Weihe, R. F. White, F. Debes, S. Araki, K. Yokoyama, K. Murata, N. Sorensen, R. Dahl and P. J. Jorgensen, Cognitive deficit in 7-year-old children with prenatal exposure to methylmercury, Neurotoxicol. Teratol., 1997, 19, 417-428; (b) R. A. Kohman and J. S. Rhodes, Neurogenesis inflammation and behavior, Brain, Behav., Immun., 2013, 27, 22-32, DOI: 10.1016/j.bbi.2012.09.003. 